\title{
Exploration of College Chinese Teaching Concept and Talent Cultivation Mode
}

\author{
Meng Yan \\ Nanchang Institute of Science \&Technology, Nanchang Jiangxi 330108, China
}

Keywords: college Chinese; teaching concept; talent cultivation mode

\begin{abstract}
In short, accomplishment refers to the sum of various internal qualities formed through people's practical training. Cultural qualities mean the relatively stable and internal basic ones that people have in cultural aspect. Chinese teaching and talent cultivation mean the total abilities to apply Chinese teaching concept and inherit traditional morality through the study of Chinese teaching concept, qualities and individual characteristics. College Chinese teaching and talent cultivation are compound words. They include college students' basic recognition of Chinese teaching, abilities to inherit traditional morality and methods to apply concept. Students' level of Chinese teaching and talent cultivation is always reflected by their mental outlook, external temperament, cultural taste and so on. After thousands of years of inheritance and development, excellent Chinese teaching concept has gathered generations' wisdom, providing important resources for contemporary Chinese teaching and talent cultivation. They play a vital role in enriching college students' knowledge, cultivating minds, improving ideology and morality. College Chinese teaching and talent cultivation are helpful to promote students' initiative, enthusiasm and creativity in inheriting and innovating Chinese teaching concept.
\end{abstract}

\section{Introduction}

With the development of modern economy and the deepening of globalization, great changes have taken place in college students' values, life attitudes, ways of thinking and behavior habits or there are even some negative phenomenon, all of which make Chinese teaching and talent cultivation gradually disappear among contemporary college students.

Chinese teaching concept in our country is the result of Chinese nation's great practice and the crystallization of five thousand years' civilization. It is an ideological system formed by the integration of Confucianism, Buddhism and Taoism. It also contains local customs, traditional customs, religious beliefs and other components, reflecting Chinese national characteristics and looks. In the term of contents, it does not only include Four Books and Five Classics, ancient philosophers, poetry of Tang and Song Dynasties, verse in Yuan Dynasty, novels of Ming and Qing dynasties, but also include Chinese traditional calligraphy, painting and opera art etc. Besides, it does not only contain material, spiritual and institutional culture like cultural relics, religious beliefs and ethics, but also behavioral culture such as clothing, food, architecture, festival and other factors. From the point of characteristics, Chinese teaching concept is unique to China with distinct nationality and different from other national cultures. It spans five thousand years of Chinese history, having rich and colorful connotations. Although the development of Chinese teaching concept varied more or less in difference historical periods, on the whole, it seems that the development is not absolute and has its own historical inheritance. In view of the nature of Chinese teaching concept, excellent Chinese teaching concept is the essence, playing a positive role in national prosperity, national rejuvenation, social harmony and personal growth. It worth our attention that because the Chinese teaching concept is the product of feudal society, there is inevitably feudal dross, such as "royalty and loyalty", "three cardinal guides and five constant virtues" and so on. These backward feudal thoughts still bind people, hindering social progress. Therefore, we must correctly distinguish essence from dross when dealing with Chinese teaching concept, so as to "select the essence and discard the dregs","bring forth the new and reform the old". 


\section{Methods to Cultivate College Students’ Accomplishment of Chinese Teaching Concept}

In order to cultivate college students' accomplishment of Chinese teaching concept, we need to put forward and implement concrete and effective measures from four aspects: society, government, school and family. It will be helpful to improve the accomplishment of college students' Chinese teaching concept and provide high quality application talents for the modernization construction of our country.

\subsection{Intuitive communication of TV}

TV has several practical roles such as audio-visual function, rapid communication and powerful appeal. It is the current most influential propagation medium, playing an important role in cultural communication. For example, "Chinese Dictation Conference" and "The Reader" set up by CCTV insist the correct guidance, inherit Chinese teaching concept and show its charm. These cultural and educational programs, to some extent, bring Chinese teaching concept back to the public sight. It is well known that contemporary college students have a lot of leisure time which allows them to look for various entertainment ways, including watching serial. A majority of students have no interest in boring educational programs. Therefore, in order to meet their watching requirements and psychological consensus, programs related to Chinese teaching concept must incorporate rich and interesting elements, realizing the combination of education and entertainment, passing on positive mainstream thoughts.

\subsection{Indirect penetration of network}

It is not hard to find that communication technology and means are two important factors for the survival and development of Chinese teaching concept. Modern transformation of the concept should "make Chinese teaching concept blend continuously with modern ways". With the arrival of network era, network culture has gradually penetrated into daily life of college students as a new cultural form. It has become an important channel for students to obtain knowledge, information and resources. Therefore, in talent cultivation, on one hand, we should construct an official network platform for excellent Chinese teaching concept, providing better service for college students so that they can achieve Chinese teaching concept resources and learn classics. On the other hand, we need to develop online games with the nature of learning to attract students' attention and enhance their interests in learning Chinese teaching concept.

It is beneficial to participate in various cultural thematic activities. First, academic activities are suggested. To carry out cultural and artistic public welfare training and lectures or to invite famous teachers to read, comment and so on. Through these activities, new learning spirit can be built and students' reading interest will be greatly enhanced. Second, practical activities are proposed. To promote traditional drama and calligraphy into campus or play red movies or small classical concerts for free. These will make students have more vivid understanding of historical culture, improve their knowledge and cultivation of excellent Chinese teaching concept.

"Education is the cornerstone of national rejuvenation and social progress". College is the place to educate. General Secretary Xi Jinping has stated on different occasions that Chinese teaching concept should have the important functions of establishing morality, cultivating and educating people. Colleges need to attach great importance to Chinese talent cultivation, regarding the cultivation of students' Chinese teaching concept accomplishment as a vital task. It is necessary to change educational thoughts, re-recognize the importance and urgency of setting up Chinese teaching concepts courses, perfect curriculum structure, desalinate the boundary between professional and humanistic curriculum and promote interdisciplinary integration. It is also important to bring talent cultivation into the whole structure of curriculum system, penetrate Chinese teaching concepts into every step of classroom and practical teaching, further set up elective courses, make a systematical and deep introduction of concrete contents of Chinese teaching concept and construct characteristic courses.

It is important to establish a specialized leadership organization and a professional teacher team to pread Chinese teaching concept. The biggest impact on college students' Chinese teaching 
concept is no more than from educators. Professional teachers have deep theoretical foundation and solid professional foundation. When guiding students to learn, they have obvious advantages. Teachers engaged in talent cultivation should have profound knowledge and elegant aesthetic taste. They should pay attention to the cultivation of aesthetic taste, read elegant classics, contact the wise, "communicate with intellectuals", pay attention to cultural taste, temperament and cultivation, as well as improve their own cultural accomplishment. At the same time, teachers need to improve their ability to sum up social experience, raise experience to the height of culture, enlighten college students' life, help them to better understand the meaning and value of Chinese teaching concept, and set a positive example for students. Teachers are required to match their actions with words, internalize the ideology and culture of Chinese teaching concept as accomplishment, externalize them as behaviors, use the concept to guide their behaviors, in particular Chinese traditional moral thoughts, pay attention to words and deeds, influence and motivate students with their own behaviors, and set up a noble personality image for students.

In some colleges, education of Chinese teaching concept is considered as a form to cope with inspection. It is quite urgent to establish a long-term mechanism to promote the study and perfect related management system of talent cultivation. For example, it is feasible to take college students' participation in Chinese teaching concept into assessment and establish an incentive system for teachers to spread the concept, giving full play to the role of cultural landscape in the cultivation of students' Chinese teaching concept accomplishment, creating an atmosphere in which college campuses carry the information of Chinese teaching campus as well as humanistic arts and integrating excellent concept into campus to the utmost. At the same time, with the development of network, digital reading has become a trend and it is a brad new reading method, gaining more and more students' usage and favor. By enhancing and prompting cultural education work related to Chinese teaching concept reading in digital environment, colleges are supposed to carry out related reading activities while campus official website provides a platform to interact and push forward classics.

Family is an indispensable environment for everyone's growth and plays a vital role in the cultivation of students' Chinese teaching concept. For a long time, family neglects the inheritance of Chinese teaching concept as well as the important positive influence of excellent concept. As a result, a part of contemporary college students lack the ability to internalize and understand the concept. Thus, it can be seen that changing parents' utilitarian view of talents and education, as well as forming correct family educational concept will be favorable to develop correct family educational concept, students' comprehensive development, the cultivation of Chinese teaching concept accomplishment and the inheritance of traditional virtues.

The method of "instructing and influencing others by one's words and deeds" is an important family education way. On one hand, family education should pay more attention to "instruct and influence others by one's words". In daily family life, parents can often chat with their children about the topics of Chinese teaching concept. This will infiltrate related knowledge into children's deep consciousness, forming a habitual force. On the other hand, family needs to stress "Instructing and influencing others by one's deeds”. In family, parents are suggested to set up a good example for children through daily behaviors which are helpful to cultivate children to be thrift and respect the old and cherish the young.

In order to improve Chinese teaching concept accomplishment, college students should firstly cultivate interests to learn these knowledge. Because interest is the best teacher which will fully arouse initiative and enthusiasm to learn concept. On one hand, they are suggested to learn traditional skills such as calligraphy, painting, musical instruments and so on. Through these traditional skills, students are able to feel the charm of excellent Chinese teaching concept. It worth our attention that students should also study excellent concept more comprehensively and profoundly, understand the broad and profound connotation and further enhance the ability to internalize the concept into cultural accomplishment and externalize it into moral behaviors.

College students have a high cultural knowledge level and strong ability to understand and analyze problems. They play an important role in cultural inheritance of Chinese teaching concept. 
Students should consciously assume the historical mission of inheriting and innovating Chinese teaching concept and contribute their own strength to achieve the great rejuvenation of Chinese nation. By enhancing college students' Chinese teaching concepts accomplishment, they will inherit and carry forward the essence, promoting their innovative development and creative transformation.

People's accomplishment is cultivated and enhanced in practice. Therefore, in order to play students' subjective function in cultivating Chinese teaching concept, we need to continuously improve their moral cultivation and practical ability. On one hand, college students should actively absorb traditional cultivation theory and use it to guide themselves to improve moral cultivation and strengthen the cultivation of cultural accomplishment of Chinese teaching concept. On the other hand, students need to pay attention to improve practical ability, actively participate in practical thematic activities, externalize the internalized qualities and morality as practical behaviors and consolidate their cultural accomplishment of Chinese teaching concept through cultural activities.

\section{References}

[1] Dong Zefang, Wang Xiaohui. Common Characteristics and Enlightment of Talent Cultivation Mode in Foreign First-class Universities-Based on the Experience Analysis of Outstanding Talent Cultivation in Eight First-class Universities [J]. Journal of National Academy of Education Administration, 2014(04).

[2] Liu Zhaoqing, Zhao Min. Research on Engineering Students' Internship Status in Enterprises Based on Situational Cognition Theory [J]. Research in Higher Education of Engineering, 2013(02).

[3] Xu Lin, Yang Chuangui. Research and Enlightment of Scientific Innovation Mechanism in German Universities Based on Heuristic Teaching-Take Munich Polytechnic University as an Example [J]. China Construction Education, 2012(06). 